\title{
DESENVOLVIMENTO GEOGRÁFICO DESIGUAL E PLANEJAMENTO EM SANTA CATARINA: A POLÍTICA CATARINENSE dE CIÊNCIA, TECNOLOGIA E INOVAÇÃo
}

\author{
Ivo Marcos Theis' \\ Ana Cláudia Moser² \\ Diego Boehlke Vargas ${ }^{3}$
}

\begin{abstract}
Resumo
A relação entre o desenvolvimento geográfico desigual e o planejamento em Santa Catarina pode ser analisada através dos elementos que compõem a Política Catarinense de Ciência, Tecnologia e Inovação. Este trabalho parte da hipótese de que a influência da visão dominante de C\&T, contida no planejamento governamental catarinense mais recente, favorece a dinâmica de desenvolvimento geográfico desigual em Santa Catarina. A análise debruça-se sobre a Lei de Inovação do Estado de Santa Catarina e o documento da PCCTI à luz da crítica à cadeia linear de inovação e do conceito de desenvolvimento geográfico desigual. Há um domínio da C\&T em sua forma convencional, nas últimas décadas, funcional às necessidades do sistema capitalista. Logo, o planejamento em C\&T em Santa Catarina no período, por não alterar sua dinâmica, parece contribuir para o desenvolvimento geográfico desigual.
\end{abstract}

Palavras-chave: Santa Catarina. Planejamento regional. Ciência \& Tecnologia.

Classificação JEL: O38, R58.

Economista, doutor em Geografia pela Universität Tübingen [Alemanha], professor da Universidade Regional de Blumenau [FURB], coordenador do Núcleo de Pesquisas em Desenvolvimento Regional e pesquisador do CNPq, e-mail: theis@furb.br

2 Cientista social, mestranda em Desenvolvimento Regional do Programa de Pós-Graduação em Desenvolvimento Regional [PPGDR] da FURB e integrante do Núcleo de Pesquisas em Desenvolvimento Regional, e-mail: aninhamoser@gmail.com

3 Economista, mestrando em Desenvolvimento Regional do PPGDR da FURB e integrante do Núcleo de Pesquisas em Desenvolvimento Regional, e-mail: vargasdb@gmail.com 
Desenvolvimento geográfico desigual e planejamento em Santa Catarina: a Política Catarinense de Ciência, Tecnologia e Inovação

\section{INTRODUÇÃO}

No processo histórico de elaboração e execução da política de ciência e tecnologia no Brasil, verifica-se a predominância da ciência e tecnologia (C\&T) dominante nos últimos séculos. Nessa visão o desenvolvimento científico tem sido entendido, do ponto de vista do senso comum e dos atores ligados à ciência e tecnologia, como fator que leva ao desenvolvimento e ao bem estar, decorrentes de ações da cadeia tecnológica. Esse contexto conduz a ideia de que na cadeia linear de inovação a pesquisa básica conduz à pesquisa aplicada que, por sua vez, conduz a inovações, levando, assim, ao desenvolvimento econômico e social. No entanto, percebe-se uma dissociação entre a política científico tecnológica e a política econômica e social.

As atividades científicas e tecnológicas tendem a ser distribuídas de forma desigual sobre os espaços, acompanhando a acumulação do capital, fazendo a propagação da base técnica do centro sobre outros espaços, dinamizando e reforçando a capacitação técnico científica do centro. Esse processo não se dá de forma linear, como mostra o caso brasileiro e reflete-se em Santa Catarina no período recente. Tal fenômeno resulta da dinâmica socioeconômica excludente, tanto no que diz respeito ao desenvolvimento científico e tecnológico, quanto no desenvolvimento econômico e social.

A hipótese deste trabalho é que a influência da visão dominante de C\&T contida no planejamento governamental mais recente favorece a dinâmica do desenvolvimento geográfico desigual em Santa Catarina. Nessa perspectiva, o problema a ser tratado é o planejamento regional e a Ciência e Tecnologia, sobretudo, a Política Catarinense de Ciência, Tecnologia e Inovação e sua relação com o desenvolvimento desigual em Santa Catarina. Para tanto serão analisadas as referências à C\&T nos planos de Governo do Estado de Santa Catarina, com especial atenção à Lei de Inovação do Estado de Santa Catarina e ao documento da PCCTI, à luz da crítica à cadeia linear de inovação e do conceito de desenvolvimento geográfico desigual.

Para dar conta deste propósito, o presente artigo foi dividido em sete seções: após esta introdução, na segunda seção, apresenta-se o referencial teórico da teoria do desenvolvimento geográfico desigual; as duas seções 
seguintes procuram abordar criticamente os conceitos de planejamento e ciência e tecnologia; a quinta seção trata da relação entre a política científica e tecnológica e o desenvolvimento geográfico desigual; na sexta seção faz-se a análise do planejamento e da ciência e tecnologia em Santa Catarina, com atenção à lei de inovação e à política catarinense de ciência, tecnologia e inovação; e a última seção, finalmente, reserva-se às considerações finais do artigo.

\section{A TEORIA DO DESENVOLVIMENTO GEOGRÁFICO DE- SIGUAL}

A expansão e a exploração do espaço geográfico pela burguesia podem ser identificadas desde o surgimento do capitalismo e com mais velocidade desde a Revolução Industrial. Esse movimento levou à exploração do mercado mundial e, ao mesmo tempo, deu um caráter cosmopolita tanto à produção quanto ao consumo ao redor do mundo. Após a década de 1970 a economia capitalista passou por mais um processo de expansão no qual a indústria moderna configuraria uma divisão territorial do trabalho própria do sistema capitalista (THEIS; BUTZKE, 2009).

A origem da noção de desenvolvimento desigual remete aos escritos de Lênin, nas análises políticas do desenvolvimento capitalista na Rússia, adquirindo maior importância na obra de Trotsky. A lei do desenvolvimento desigual pode ser utilizada tanto para compreender as transformações das formações, quanto às contradições econômicas e sociais dos países capitalistas periféricos. Nesse contexto a tentativa dos países periféricos de alcançar os países desenvolvidos levou ao desenvolvimento desigual. No entanto, essa tentativa pode ser realizada pulando etapas consideradas intermediárias desse processo. Dessa maneira esses países periféricos se desenvolvem de forma desigual quando comparados aos países centrais. A irregularidade do desenvolvimento entre os países é o que se pode chamar de lei do desenvolvimento desigual e combinado (LÖWY, 1995).

Entretanto, para Neil Smith (1988) a teoria do desenvolvimento desigual concentra sua preocupação com o processo e o padrão do desenvolvimento desigual especificamente capitalista, afirmando-se como uma lei universal da história humana, ou de forma abstrata à essência da contradição. Levando em 
Desenvolvimento geográfico desigual e planejamento em Santa Catarina: a Política Catarinense de Ciência, Tecnologia e Inovação

consideração que a geografia do capitalismo é uma parte integral do modo de produção, o espaço passa a ser um conceito chave para a compreensão do sistema capitalista. As características da geografia sustentam as explicações para o desenvolvimento desigual comercial e político de regiões e nações.

Por sua vez, o conceito de desenvolvimento geográfico desigual é mais recente e se encontra na teoria do desenvolvimento desigual. A diferença fundamental entre a lei do desenvolvimento desigual e combinado da teoria do desenvolvimento geográfico desigual está na ênfase da primeira em explicar por que uma formação social periférica, onde as forças produtivas não estão desenvolvidas e nem são controladas pela burguesia nacional, pode vivenciar uma revolução política; já no segundo, a ênfase está na tentativa teórico-metodológica de conceber a natureza geográfica da desigualdade econômica entre regiões e países produzida pelo capitalismo (THEIS; BUTZKE, 2009).

Aqui, dois elementos são centrais (HARVEY, 2004): a produção das escalas espaciais e a produção da diferença geográfica. A produção das escalas espaciais diz respeito a produção de uma hierarquia de escalas espaciais que organiza as atividades humanas. A produção da diferença geográfica é resultante da conformação de um mosaico geográfico ambiental ao redor do mundo, por um lado, e pela forma como essas diferenças geográficas são modificadas pelos processos político-econômicos e socioecológicos que ocorrem atualmente. É importante compreender de que modo as diferenças geográficas estão sendo produzidas no presente, quanto compreender os processos ocorridos no passado, em outros ciclos de atividade.

\section{O CONCEITO DE PLANEJAMENTO}

Uma manifestação desses processos remonta às origens do planejamento e sua evolução ao longo do século XX. As práticas de planejamento podem ser reconhecidas, pois, como um elemento que favoreceu a produção capitalista do espaço. Isto é, contribuíram à produção de escalas espaciais e, consequentemente, de diferenciações geográficas.

As cidades europeias do início do século XIX conviviam com o caos urbano estabelecido pelo capitalismo - e agravado pela Revolução Industrial. À medida que uma ordem social ia tornando-se predominante, 
a reificação do espaço e das pessoas pelo planejamento urbano tornou-se incontestável e irreversível.

Logo, o planejamento no capitalismo foi transformando tudo e todos em mercadorias, e os processos econômicos fizeram com que esta base de raciocínio, apoiada em planejamento (empresarial e econômico-governamental), se tornasse cada vez mais sólida, rígida e instrumental: "o planejamento redefine a vida social e econômica segundo critérios de racionalidade, eficiência e moralidade que são consoantes com a história e as necessidades do capitalismo e da sociedade industrial." (ESCOBAR, 2000, p. 214).

A utilização do planejamento de forma mais abrangente que surge na Rússia, entre 1917 e 1930, como um plano quinquenal para toda a economia, recebe novas técnicas e métodos e é adequado aos países do Terceiro Mundo, cujas economias almejavam uma industrialização rápida, notadamente nas décadas de 1950 e 1960 - bem como o caso brasileiro. Todavia, o que ocorre ali, é que se tratava de criar condições para a produção e reprodução capitalista; de alterar as estruturas humanas e sociais existentes por outras. Por outro lado, há experiências de planejamento pelas quais se viu a necessidade de contribuir aos países capitalistas destruídos pela Segunda Guerra Mundial. Ali, o planejamento surge justamente para suprir necessidades econômicas e sociais. Os novos modelos de planejamento passaram a referir-se a uma nova realidade, uma realidade sobre a qual deveriam atuar políticas que conduzissem ao desenvolvimento.

Ainda que todas as possíveis definições do termo planificação, ou planejamento, cada qual com sua especificidade, levem ao mesmo fim: "alcançar o futuro" (GUILLEZEAU, 2002, p. 98), divergências no conceito apontam para variados caminhos: incertezas inerentes aos processos de planejar - "seu cálculo é nebuloso e sustenta-se na compreensão da situação" (MATUS, 1991, p. 28); metodologias de aplicação a projetos - "estabelece objetivos, define linha de ação e planos detalhados" (LOPES, 1990, p. 24); modelos sistemáticos de compreensão, pois, atua "através de um controle de vastas redes de órgãos e instituições interdependentes" (LOPES, 1990, p. 24); análises de futuro, uma vez que busca inserir-se no futuro, vivenciando-o (GUILLEZEAU, 2002). Escobar (2000, p. 213) lembra que "o planejamento requer [...] uma normatização e uma padronização da realidade, que [...] têm como corolário a injustiça e a obliteração da diferença e da diversidade". 
Desenvolvimento geográfico desigual e planejamento em Santa Catarina: a Política Catarinense de Ciência, Tecnologia e Inovação

Em termos práticos, para uma economia capitalista, "o planejamento global procura dar uma visão ampla do desenvolvimento da economia, fixando objetivos a atingir e procurando assegurar a consistência entre a oferta e a demanda de bens em todos os setores.” (LAFER, B., 1975, p. 16).

No entanto, o planejamento é inerentemente político. O planejador e o Poder Executivo poderiam andar lado a lado nas decisões e aplicações de alternativas ao sistema. No entanto, lutas por poder e de mercado têm feito dessas possibilidades meras utopias. A direção na qual se movimenta o fluxo de decisão subjaz a própria racionalidade de um modelo de planejamento, haja vista as decisões resultarem da disputa de poder entre os atores. Os administradores ou decisores públicos, por sua vez, não são neutros; sofrem influência dos agentes interessados, os quais possuem posição e grau de poder diferentes.

De um lado, encontram-se tomadores de decisão na forma de autoridades, que possuem total controle sobre o processo decisório e decidem quais e como as políticas serão implementadas. Esse modo de decisão é conhecido como top-down, pelo qual as ações são executadas e coordenadas de cima para baixo. Noutro lado, a direção do fluxo de decisões ocorre de baixo para cima (bottom-up). Aqui, são levados em consideração os sujeitos que estão mais próximos dos resultados da aplicação de uma determinada política. Quando as políticas contêm aspectos de decisão bottom-up, tanto as populações afetadas, quanto os agentes do Estado, influenciam as políticas elaboradas, democratizando o processo. Pois, parte-se da consulta pública e da participação social para a definição de prioridades da sociedade, desde as comunidades regionais até o topo hierárquico do sistema governamental. Há, porém, de se considerar a convergência dos fluxos top-down e bottom -up com o fim de um melhor entendimento das políticas públicas em sua totalidade (OLIVEIRA, 2006).

Sucintamente, a distinção ocorre, por um lado, "entre sociedades que são planejadas de cima para baixo, através de decretos governamentais - nas quais, por conseguinte, predomina o procedimento formal" e, por outro, "nas quais o planejamento é organizado de modo mais ou menos informal, desempenhando o governo apenas um papel de menor importância, porventura estratégico, no processo total de decisões da comunidade." (FRIEDMANN, 1959, p. 11). 


\section{O CONCEITO DE CIÊNCIA \& TECNOLOGIA}

A tecnologia se encontra a serviço da produção de mercadorias. Como valores de uso as mercadorias satisfazem as necessidades humanas, porém os proprietários dos meios de produção utilizam a tecnologia e a força de trabalho como valores de troca e na geração dos excedentes. Levando esse aspecto em consideração, a C\&T tende a ser peça chave na promoção do desenvolvimento econômico. Porém, o mesmo não ocorre, na mesma medida, na promoção do desenvolvimento social (THEIS, 2011).

As inovações tecnológicas são de extrema importância na produção e no reinvestimento do valor do excedente relativo, colocando a tecnologia como um instrumento central na acumulação do capital. Como capital fixo no processo de produção, a tecnologia permite o desenvolvimento e expansão do capital. A competição, por sua vez, faz com que se generalize a necessidade pela inovação em todas as áreas da economia. Dessa forma são destinados muitos recursos para facilitar o desenvolvimento e as aplicações da ciência; o progresso da ciência torna-se um negócio cujo objetivo é desenvolver constantemente o capital fixo (SMITH, 1988).

As particularidades da C\&T gerada na sociedade capitalista tendem a impulsionar o desenvolvimento econômico, mas, não de forma linear, conduzir ao desenvolvimento social (THEIS, 2009). A tecnologia produzida nesse contexto é a tecnologia convencional [TC] e possui uma série especificidades. A primeira dessas características é a relação com o trabalho: a TC poupa mais mão-de-obra do que necessário. Isto ocorre porque na tecnologia capitalista o lucro das empresas depende da redução do trabalho humano, isto é, depende da redução do tempo de trabalho socialmente necessário para produção de mercadorias.

Outra característica refere-se à escala de produção ótima sempre crescente: a cada nova onda tecnológica, gerada pelas inovações, as tecnologias produzidas ganham uma escala cada vez maior. A insustentabilidade ambiental também faz parte da TC, uma vez que não são contabilizados os danos causados ao ambiente como custo de produção. Outras externalidades, como a condição dos trabalhadores e os índices de desemprego, também não fazem parte do cálculo técnico-econômico da empresa capitalista. 
Desenvolvimento geográfico desigual e planejamento em Santa Catarina: a Política Catarinense de Ciência, Tecnologia e Inovação

A segmentação é outra característica da TC: não necessariamente para tornar o processo produtivo mais eficiente, mas para não permitir o controle do produtor sobre o processo de trabalho. Desse modo, apenas o patrão (capitalista, chefe, engenheiro) possui conhecimento total do processo produtivo, o qual torna-se alienado por não utilizar a potencialidade do produtor (DAGNINO, 2010).

Os elementos que caracterizam a TC são determinados pelo mercado dos países avançados. O conhecimento que é produzido nesses países - digase de passagem, o qual representa $95 \%$ dos gastos em pesquisa no mundo - é baseado e tem como objetivo satisfazer as necessidades do consumo de alta renda. Enquanto as novas e mais modernas tecnologias estão a serviço das demandas dos países ditos avançados, as tecnologias que estão em uso nos países pobres - as quais servem para satisfazer necessidades básicas, produzir infraestrutura ou gerar valor às matérias-primas - encontram-se paradas no tempo. Dessa forma, não há como falar em C\&T neutra (DAGNINO, 2010). A C\&T, especialmente em sua forma convencional, está a serviço do capitalismo e também se desenvolve baseada na crença na cadeia linear de inovação.

\section{POLÍTICA CIENTÍFICA E TECNOLÓGICA NO CONTEXTO DO DESENVOLVIMENTO GEOGRÁFICO DESIGUAL}

A relação entre planejamento e desenvolvimento geográfico desigual pode ser observada através da análise da Política Científica e Tecnológica [PCT]. De forma geral, a PCT conforma a distribuição das atividades científicas e tecnológicas ao longo do tempo. No entanto, essa distribuição se configurou de forma desigual no território, acompanhando a acumulação do capital. A base técnica se propagou do centro sobre outros espaços, dinamizando e reforçando a capacitação técnico-científica do centro. No contexto nacional desde a década de 1980 são verificados esforços oriundos da PCT em direção à passagem da pesquisa básica para a aplicada, e na inserção na economia capitalista mundializada. A partir da década de 1990, a ênfase está na inclusão social.

De acordo com Dagnino; Dias (2007) para a compreensão da relação entre o histórico da PCT no país e a dificuldade de alcançar um modelo de 
desenvolvimento mais igualitário no território é imprescindível considerar a agenda do processo decisório. Para explicar o sucesso ou fracasso de uma política são consideradas duas dimensões. Na primeira são considerados os atores do processo decisório, aqui se busca analisar como o ator dominante atua para contemplar seus interesses. Na segunda dimensão são identificadas as falhas de formulação e implementação da política. A partir dessas dimensões é possível compreender como a PCT no país não alcançou seus objetivos da forma prevista.

Na década de 1970 a PCT esteve pautada numa agenda distanciada de outras políticas, pela qual os assuntos de interesse do governo não eram incorporados à PCT. A agenda da empresa tinha menor representação, pois nosso modelo de capitalismo periférico não gerava uma demanda interna por C\&T - ao contrário do processo ocorrido nos países desenvolvidos. A participação limitada desses atores consolidou uma agenda de PCT centrada na agenda da ciência. Nesse período os temas clássicos de interesse da comunidade científica eram os temas fundamentais para pensar em desenvolvimento socioeconômico.

Apenas no final da década de 1980 que a agenda da empresa conquista espaço na PCT. Essa abertura se deve aos burocratas partidários da Teoria da Inovação, que introduziram no processo decisório temas de interesse da empresa, objetivando desenvolvimento econômico. O espaço para a discussão dessas questões foi aberto pela comunidade de pesquisa, demonstrando claro interesse em interagir com as empresas nacionais inovadoras e também com multinacionais intensivas em tecnologia. A crença era que essa interação entre universidades e empresas poderia legitimar socialmente as atividades de pesquisa desenvolvidas na universidade. Esse argumento se tornou hegemônico na PCT e levou a criação de arranjos institucionais de incentivo a interação entre a universidade e as empresas (parques e pólos tecnológicos, incubadoras, projetos cooperativos, mecanismos para estimular a absorção de pessoal pós-graduado pelas empresas).

$\mathrm{O}$ fator que proporcionou o equilíbrio entre os aspectos apresentados foi o modelo cognitivo que amparou a concepção de PCT. Esse modelo é sustentado pela idéia de que, especialmente no plano econômico, o conhecimento produzido na sociedade deve chegar às empresas e retornar em forma de benefícios para a sociedade. E, também, de que a inovação no processo 
Desenvolvimento geográfico desigual e planejamento em Santa Catarina: a Política Catarinense de Ciência,

Tecnologia e Inovação

de maximização dos lucros leva a um círculo vicioso de competitividade nas empresas e em outros espaços como as nações e na busca pelo bem-estar dos cidadãos. Outra idéia do senso comum associada a esse modelo é de que a tecnociência é neutra, mesmo que esse pressuposto venha sendo refutado ao longo da história pelos pesquisadores, a neutralidade e o determinismo ainda ocupam posição central no modelo cognitivo da PCT (DAGNINO; DIAS, 2007).

Ao relacionar a PCT com as desigualdades é importante considerar que a política se articula com os processos de exclusão social em três níveis estreitamente relacionados: a relação Estado-Sociedade; o plano formal das políticas e instituições que materializam a relação Estado-Sociedade; e o plano que compreende relações particulares entre a C\&T e o processo de desenvolvimento brasileiro.

Analisando o contexto geral da PCT no Brasil percebe-se que, mesmo com a crescente importância da passagem da pesquisa básica para a aplicada, da pesquisa e desenvolvimento no setor produtivo privado e da progressiva entrada da "inclusão social" na PCT, esses são pontos que, na prática, não avançaram suficientemente. Por esse motivo são questões recorrentes na PCT. Dessa forma, pode-se afirmar que desenvolvimento científico e tecnológico no país contribui de forma pouco significativa para o desenvolvimento social, reforçando as desigualdades e o desenvolvimento geográfico desigual. A configuração das desigualdades no país apresenta o retrato resultante da conformação inter-regional gerada pelo desenvolvimento geográfico desigual.

\section{PLANEJAMENTO E CIÊNCIA \& TECNOLOGIA EM SANTA CATARINA}

A história do planejamento no Estado de Santa Catarina inicia-se na década de 1960. Há uma semelhança nos rumos tomados pelo planejamento, sobretudo, governamental, no nível estadual e nacional. O planejamento governamental brasileiro ganhava relevância em fins da década de 1950 com o Plano de Metas no governo de Juscelino Kubitscheck (LAFER, C., 1975). No entanto, a região privilegiada foi a Sudeste do país. Pela trajetória tomada a partir do planejamento em nível federal é que se desperta para a 
necessidade de intervenção estatal por parte do governo de Santa Catarina. Ali, o objetivo era o desenvolvimento econômico, pelo qual se buscaria superar a condição de Estado periférico.

Ademais, como se verá a seguir, somente mais recentemente se percebe em Santa Catarina uma referência explícita à Ciência e Tecnologia nas práticas de intervenção do Estado na sociedade.

O planejamento econômico governamental catarinense se consolida e se expande, portanto, a partir de 1960 com o I Plano de Metas do Governo [I PLAMEG] (SCHMITZ, 1985). Entretanto, na verdade, ocorre uma mudança na forma de atuação do agente estatal, o qual passa a conceder incentivos, créditos, formação profissional, infra-estrutura etc. Assim, o I PLAMEG favoreceria o enriquecimento privado nos marcos de um modelo que, aos poucos, revelar-se-ia excludente e concentrador de rendas em Santa Catarina.

No Quadro 1 apresentam-se, sucintamente, os planos estaduais de 1966 a 2002, todos baseados numa lógica estritamente estatal.

\begin{tabular}{|c|c|c|c|}
\hline Período & Plano & Governo & Características \\
\hline $\begin{array}{l}1966 \text { a } \\
1970\end{array}$ & II PLAMEG & Ivo Silveira & $\begin{array}{l}\text { Impulso ao crescimento econômico, } \\
\text { mas pouca atenção à área social }\end{array}$ \\
\hline $\begin{array}{l}1971 \mathrm{a} \\
1974\end{array}$ & $\begin{array}{l}\text { Projeto Catarinense de } \\
\text { Desenvolvimento }\end{array}$ & $\begin{array}{l}\text { Colombo } \\
\text { Machado Salles }\end{array}$ & $\begin{array}{l}\text { Parceria com as doze AM } \\
\text { existentes; baseado no I PND }\end{array}$ \\
\hline $\begin{array}{l}1975 a \\
1978\end{array}$ & Plano de Governo & $\begin{array}{l}\text { Antônio Carlos } \\
\text { Konder Reis }\end{array}$ & $\begin{array}{l}\text { Aumento da participação no } \\
\text { processo decisório, mas ênfase na } \\
\text { acumulação de capital privado }\end{array}$ \\
\hline $\begin{array}{l}1979 a \\
1982\end{array}$ & Plano de Ação & \begin{tabular}{|l} 
Jorge Konder \\
Bornhausen
\end{tabular} & $\begin{array}{l}\text { Descontinuidade nos processos de } \\
\text { execução }\end{array}$ \\
\hline $\begin{array}{l}1983 a \\
1986\end{array}$ & $\begin{array}{l}\text { "Carta aos } \\
\text { Catarinenses" }\end{array}$ & Esperidião Amin & $\begin{array}{l}\text { "Prioridade aos pequenos" como } \\
\text { meta, mas apenas em discurso }\end{array}$ \\
\hline $\begin{array}{l}1987 a \\
1990\end{array}$ & $\begin{array}{l}\text { "Rumo à Nova } \\
\text { Sociedade Catarinense" }\end{array}$ & $\begin{array}{l}\text { Pedro Ivo } \\
\text { Campos }\end{array}$ & $\begin{array}{l}\text { Integração do Governo com } 17 \\
\text { seminários regionais }\end{array}$ \\
\hline $\begin{array}{l}1991 \text { a } \\
1994\end{array}$ & Plano SIM & $\begin{array}{l}\text { Vilson } \\
\text { Kleinübing }\end{array}$ & $\begin{array}{l}\text { Atenção à saúde, instrução e } \\
\text { moradia, mas seguindo orientações } \\
\text { da "onda" neoliberal }\end{array}$ \\
\hline \begin{tabular}{|l|}
$1995 a$ \\
1998
\end{tabular} & $\begin{array}{l}\text { Plano Viva Santa } \\
\text { Catarina }\end{array}$ & $\begin{array}{l}\text { Paulo Afonso } \\
\text { Vieira }\end{array}$ & $\begin{array}{l}\text { Acordos com ONG, prefeituras e } \\
\text { empresas privadas }\end{array}$ \\
\hline $\begin{array}{ll}1999 a \\
2002\end{array}$ & $\begin{array}{l}\text { "Santa Catarina: Estado } \\
\text { Vencedor" }\end{array}$ & Esperidião Amin & $\begin{array}{l}\text { Pouca articulação com a realidade } \\
\text { concreta }\end{array}$ \\
\hline
\end{tabular}

Quadro 1 - Planejamento governamental em Santa Catarina, 1966 a 2002

Fonte: Elaboração dos autores com base em Schmitz (1985), Ferreira Filho (1990), Michels (1998) e Goularti Filho (2005). 
Desenvolvimento geográfico desigual e planejamento em Santa Catarina: a Política Catarinense de Ciência, Tecnologia e Inovação

Cabe revelar, no entanto, que o planejamento em Santa Catarina vem apresentando movimentos de descentralização, ainda que modestos, desde a década de 1960, aprofundando-se a partir de 1990. A primeira Associação de municípios foi criada em 1961 e procurava uma maior articulação entre os municípios e fortalecimento dos governos em nível regional e local. Atualmente, são 21 Associações, que, do assessoramento técnico aos municípios, foram integrando-se às estratégias de desenvolvimento municipal (BUTZKE, 2007; MARCON; MARQUES, 2001).

Mas essa não se trata de uma alternativa isolada à logica top-down de planejamento já predominante. Foram criados, na década de 1990, os chamados planos territoriais, os Planos regionais de desenvolvimento e os Fóruns de Desenvolvimento Regional [FDR]. Entre os mais relevantes planos territoriais, incluem-se: Política de Desenvolvimento Regional e Urbano para Santa Catarina [PDRU]; Atlas de Santa Catarina; Santa Catarina, estado onde investir; O Programa Integrado de Desenvolvimento Sócio-Econômico [PIDSE]; Plano Básico de Desenvolvimento Regional [PBDR]; Plano Básico de Desenvolvimento Ecológico-Econômico [PBDEE]; Zoneamento Ecológico Econômico [ZEE]; Plano de Gerenciamento Costeiro (SANTA CATARINA, 1990; SANTA CATARINA; FORTES, 1981; SIEBERT, 2001).

Esses planos buscaram o diálogo e a organização dos agentes à escala regional e local. Embora a maioria se assemelhasse a diagnósticos físicoterritoriais, mas com interesse municipal, outros, se destacaram pela sua continuidade, como o PBDR e o PBDEE, que cobriram um período de dois governos, de 1992 a 1999.

Por meio do PBDR/PBDEE, formularam-se no período, conjuntamente entre o Governo e as Associações de Municípios 18 Planos Regionais de Desenvolvimento. O planejamento regional representou o respeito às peculiaridades de cada região, evitando os erros da centralização estatal, pois, essa experiência teria como objetivo reforçar o associativismo municipal que se enraizava pelo Estado (SANTA CATARINA; FECAM; AMUNESC, 1993).

Com objetivo similar às Associações e aos Planos Regionais fora a criação dos FDR (o primeiro, em 1996), bem como do Fórum Catarinense de Desenvolvimento [FORUMCAT]. É importante lembrar que os 16 FDR criados buscavam praticar um planejamento regional não-estatal. Os Fóruns foram importantes arenas de articulação de entidades públicas e privadas 
com objetivo de desenvolvimento regional e sustentável e se encontram em fase de transição para Agências de Desenvolvimento Regional [ADR] (BIRKNER, 2004; SIEBERT, 2001).

O que se passa é que até então, pouca, ou quase nenhuma, referência havia sido feita a uma Política de Ciência e Tecnologia para Santa Catarina. Até então.

Em janeiro de 2003, Luiz Henrique da Silveira assumiu o Governo do Estado de Santa Catarina. Sua posse foi marcada pela Reforma Administrativa apresentada na Lei Complementar $\mathrm{N}^{\circ} 243$, de 30 de janeiro (SANTA CATARINA, 2003). O objetivo ali foi de democratizar por meio da descentralização administrativa. Até 2007, pela Lei Complementar $\mathrm{N}^{\circ}$ 381 (SANTA CATARINA, 2007), 36 Secretarias de Estado de Desenvolvimento Regional [SDR], e seus respectivos Conselhos de Desenvolvimento Regional [CDR] foram criados com a promessa de um planejamento de médio e longo prazo.

Todavia, o que é relevante aos propósitos deste artigo, surge na atenção dada, explicitamente, à dimensão da Tecnologia, pelo Plano de Governo desse período e, sobretudo, à sintonia exigida às 36 SDR geograficamente situadas pelo território catarinense na execução dessa proposta.

Em 2005, a Secretaria de Planejamento, Orçamento e Gestão do Estado iniciou a elaboração do Plano Estratégico Master Plan. Pelo plano, buscouse avaliar a competitividade das principais atividades produtivas e definir quais dessas atividades e quais regiões deveriam ser privilegiadas pelo Governo com o fim de dirimir os gargalos que dificultavam o desenvolvimento socioeconômico no Estado. Como início desse trabalho elaborou-se o Relatório Preliminar: Indicações Estratégicas, pela Fundação Universitária José Bonifácio, que indicou diretrizes para investimentos e desenvolvimento ou, conforme especificamente no texto do relatório:

o trabalho propõe ações no sentido de explorar as potencialidades mais importantes da economia catarinense, que são a vocação exportadora, a grande participação de produtos industrializados na pauta de exportações, a forte estrutura portuária e a evidente vocação para a prestação de serviços portuários em sua área de influência, [...] as condições adequadas para o desenvolvimento de um cluster de alta tecnologia, e a vocação turística (SANTA CATARINA; JOSÉ BONIFÁCIO, 2005). 
Desenvolvimento geográfico desigual e planejamento em Santa Catarina: a Política Catarinense de Ciência, Tecnologia e Inovação

Segundo as vocações e características da economia catarinense, as áreas que deveriam ser referência à definição de uma estratégia de ação do Governo Estadual eram: Logística de Transportes, Energia, Ciência \& Tecnologia (Polo de Alta Tecnologia) e Finanças. Todavia, como se trata de um diagnóstico da realidade catarinense, dependem de decisão política do Governo.

Em convergência à área de Ciência \& Tecnologia do Master Plan, foi elaborado um trabalho de análise socioeconômica do Estado de Santa Catarina, nomeado como Programa Estratégico de Desenvolvimento com Base em Inovação. Sua realização deu-se em conjunto com a Universidade Federal de Santa Catarina [UFSC], a Universidade Federal do Rio de Janeiro [UFRJ] e o Governo do Estado de Santa Catarina. O estudo foi produzido no âmbito do Núcleo de Economia Industrial e da Tecnologia [NEITEC/ UFSC] do Departamento de Economia do Centro Sócio-Econômico da UFSC em conjunto com o Programa de Pós-Graduação em Economia da UFSC [PPGE/UFSC], e teve como objetivo analisar os Arranjos Produtivos Locais e as Cadeias Produtivas Regionais selecionadas de Santa Catarina. Ademais, os resultados do diagnóstico deveriam apoiar a elaboração e implementação de ações de planejamento nas recentemente criadas SDR (UFSC/PPGE, 2005).

Subsequentemente, em 2006, atendendo ao disposto no artigo 10 da Lei Complementar $\mathrm{N}^{\circ} 284$ (SANTA CATARINA, 2005), vem à superfície o Plano Catarinense de Desenvolvimento [PCD/2015]. O PCD/2015 consiste em um conjunto de diretrizes e estratégias que visam orientar a ação governamental de 2007 até 2015 . Tomou-se como base de formulação para a SEPLAN e as outras Secretarias do Governo e CDR, os insumos fornecidos pelo Plano Estratégico Master Plan (2005) e a parceria das SDR com o Projeto Meu Lugar (2003) - o qual estabeleceu cooperação técnica com equipe do Programa das Nações Unidas para o Desenvolvimento [PNUD] (PNUD, 2004). Cabe lembrar, pois, os trabalhos que envolveram o Projeto Meu Lugar permitiram elaborar Planos de Desenvolvimento Regional para todas as novas regiões surgidas de 2003 em diante, as SDR, visando definir metas de desenvolvimento de acordo com as peculiaridades regionais.

Segundo os princípios de um planejamento de longo prazo, o PCD/2015 inspira-se num modelo de desenvolvimento sustentável buscando, especi- 
ficamente: (i) estabelecer os fundamentos para a promoção do desenvolvimento sustentável e equilibrado do Estado; (ii) definir as diretrizes nas áreas de atuação do Estado, e; (iii) formular estratégias para que as diretrizes sejam alcançadas. Para tanto, a visão de futuro e os contextos internacional, nacional e estadual permitiram a elaboração de cenários tendenciais e normativos para quatro principais dimensões e respectivas áreas de atuação (ver Quadro a seguir).

\begin{tabular}{|l|l|l|}
\hline \multicolumn{1}{|c|}{ Dimensão } & \multicolumn{1}{|c|}{ Descrição } & \multicolumn{1}{c|}{ Área de atuação } \\
\hline $\begin{array}{l}\text { Economia e Meio } \\
\text { Ambiente }\end{array}$ & $\begin{array}{l}\text { Ações estratégicas do governo } \\
\text { para garantir o desenvolvimento } \\
\text { sustentável e a competitividade } \\
\text { sistêmica do estado }\end{array}$ & $\begin{array}{l}\text { Infraestrutura } \\
\text { Iniciativas empreendedoras } \\
\text { Agricultura e meio ambiente }\end{array}$ \\
\hline Social & $\begin{array}{l}\text { Políticas públicas e mecanismos } \\
\text { para garantir o acesso aos direitos } \\
\text { básicos e a inclusão social de todos } \\
\text { os catarinenses no processo de } \\
\text { desenvolvimento }\end{array}$ & $\begin{array}{l}\text { Saúde } \\
\text { Assistência social, trabalho } \\
\text { e renda } \\
\text { Educação e cultura } \\
\text { Segurança }\end{array}$ \\
\hline Tecnologia & $\begin{array}{l}\text { Apoio à ciência e à inovação } \\
\text { tecnológica como forma de promover } \\
\text { o desenvolvimento sustentável }\end{array}$ & $\begin{array}{l}\text { Ciência, tecnologia e } \\
\text { inovação }\end{array}$ \\
\hline Políticas públicas & $\begin{array}{l}\text { Gestão pública ética comprometida } \\
\text { com a qualidade dos serviços }\end{array}$ & Gestão pública \\
\hline
\end{tabular}

Quadro 2 - Dimensões e áreas de atuação do PCD/2015

Fonte: PCD/2015 (2006).

É pertinente aos objetivos deste artigo esclarecer a dimensão Tecnologia do PCD/2015. Como atuação na Ciência, Tecnologia e Inovação, essa dimensão procura "estimular o fortalecimento de uma rede de inovação, apoiar a melhoria nos sistemas de informações do estado nas diferentes áreas e a ampliação e consolidação dos programas e projetos voltados à inclusão digital.” (PCD/2015, 2006, p. 29). Por essa perspectiva, cinco diretrizes apontam para o aumento da capacitação científico-tecnológica nas regiões de Santa Catarina:

1) Ampliar a rede de centros de inovação, incubadoras e condomínios em todas as regionais do estado.

2) Apoiar a interação universidade-empresa-governo. 
Desenvolvimento geográfico desigual e planejamento em Santa Catarina: a Política Catarinense de Ciência, Tecnologia e Inovação

3) Estimular e apoiar os programas de pós-graduação, em nível de mestrado e doutorado, em todas as universidades catarinenses.

4) Prover condições para o aumento do número de alunos concluintes em cursos superiores nas áreas de conhecimento do novo paradigma tecnológico.

5) Ampliar a inclusão digital no estado, apoiando, principalmente, projetos que integrem as áreas de educação, desenvolvimento social, saúde e segurança

\section{LEI DE INOVAÇÃO}

A Lei de Inovação do Estado de Santa Catarina foi criada em 15 de janeiro de 2008 e dispõe sobre os incentivos à pesquisa científica e tecnológica e à inovação no ambiente produtivo no Estado. A lei é composta pelos seguintes eixos: inovação tecnológica, sistema estadual de ciência, tecnologia e inovação, estímulo à inovação nas instituições científicas e tecnológicas, núcleos de inovação tecnológica [NITS], estímulo à participação do pesquisador público na atividade de inovação, estímulo ao inventor independente, estímulo à participação das empresas na inovação tecnológica de interesse do Estado, participação do Estado em fundos de investimento em empresas inovadoras, parques tecnológicos e incubadoras de empresas inovadoras e outros ambientes de inovação, fomento à ciência, tecnologia e inovação.

Em seu artigo primeiro a Lei de Inovação estabelece o universo da C\&T e quais objetivos os incentivos em C\&T no estado devem alcançar:

\footnotetext{
Art. $1^{\circ}$ Esta Lei estabelece medidas de incentivo à pesquisa científica e tecnológica e à inovação no ambiente produtivo, visando à capacitação em ciência, tecnologia e inovação, o equilíbrio regional e o desenvolvimento econômico e social sustentável do Estado, em conformidade com os arts. 176 e 177 da Constituição do Estado de Santa Catarina (SANTA CATARINA, 2008).
}

De forma geral, a Lei de Inovação concentra esforços no incentivo ao desenvolvimento de C\&T em sua forma convencional. Entre os elementos que compõem esses esforços destacam-se o incentivo a articulação entre 
instituições públicas e privadas na busca por inovações com ênfase nas inovações do setor produtivo. Considerando que como objetivos gerais da Lei de Inovação estão o equilíbrio regional, o desenvolvimento econômico e social sustentável fica expressa a crença na cadeia linear de inovação. Mais uma vez o desenvolvimento científico e tecnológico é visto como promotor de desenvolvimento econômico e por conseqüência do desenvolvimento social.

\section{POLÍTICA CATARINENSE DE CIÊNCIA, TECNOLOGIA E INOVAÇÃO}

A Política Catarinense de Ciência, Tecnologia e Inovação [PCCTI] aprovada em 2009 tem como foco promover o desenvolvimento regional sustentável, com base na educação, ciência, tecnologia e inovação. As premissas fundamentais da PCCTI apresentam a direção que o plano deverá seguir:

1 - A educação, a cultura, o conhecimento científico e tecnológico e as inovações, no cenário atual globalizado, são essenciais ao ganho e manutenção da competitividade das empresas e organizações produtivas, à modernização do Estado e ao desenvolvimento econômico e social, com sustentabilidade ambiental;

2 - a ação fomentadora, articuladora e de apoio do Estado constitui elemento chave à CT\&I;

3 - a descentralização espacial e a desconcentração institucional do conhecimento científico e tecnológico são essenciais à redução das desigualdades sociais e à promoção do desenvolvimento regional equilibrado (PCCTI, 2010).

A primeira premissa deixa clara a importância do conhecimento científico e tecnológico para a competitividade do setor produtivo, à modernização do Estado e como promoção do desenvolvimento econômico e social, assim como a sustentabilidade ambiental. A segunda premissa enfatiza a importância da articulação e do apoio do Estado para o desenvolvimento científico e tecnológico e, a terceira, aponta para a necessidade de promover um desenvolvimento regional equilibrado através da desconcentração do conhecimento científico e tecnológico. Os três elementos que regem a PCCTI acompanham, por um lado, a tendência nacional da ênfase na promoção da 
Desenvolvimento geográfico desigual e planejamento em Santa Catarina: a Política Catarinense de Ciência, Tecnologia e Inovação

interação entre universidade e empresa, através da idéia de levar o conhecimento científico e tecnológico às empresas e organizações produtivas e, a incorporação da inclusão social e superação das desigualdades via PCT. Por outro lado, acompanha a proposta de promover o desenvolvimento regional sustentável presente no PCD/2015 (PCCTI, 2010).

O objetivo geral da política é:

\begin{abstract}
Promover o avanço do conhecimento científico, tecnológico e de inovações no ambiente produtivo, nas instituições de ensino, pesquisa e extensão, nos agentes econômicos e sociais e nos órgãos de governo, visando à qualidade de vida dos habitantes e ao desenvolvimento social e econômico do Estado de Santa Catarina, com sustentabilidade ambiental e equilíbrio regional (PCCTI, 2010, p. 39).
\end{abstract}

São apresentados 4 eixos estratégicos para alcançar os objetivos do plano: i) expansão e consolidação do sistema catarinense de CT\&I; ii) pesquisa científica e tecnológica; iii) inovação e empreendedorismo; e iv) desenvolvimento social e regional mediante CT\&I. Para tanto são apresentadas 6 linhas de ação: i) consolidação institucional do sistema catarinense de CT\&I; ii) formação de recursos humanos; iii) infra-estrutura e financiamento; iv) pesquisa e desenvolvimento; v) inovação e empreendedorismo; e vi) desenvolvimento social e regional mediante CT\&I. Assim como são fixadas 5 prioridades para 2009-2010: i) fomento à pesquisa científica e tecnológica; ii) fomento à formação e capacitação de recursos humanos para a pesquisa científica e tecnológica; iii) fomento à pesquisa em ciências agrárias e meio ambiente; iv) fomento à inovação e empreendedorismo; e v) fomento à difusão de CT\&I (PCCTI, 2010).

A PCCTI apresenta, de forma geral, uma crença na promoção do desenvolvimento econômico e social de forma sustentável, buscando o equilíbrio das desigualdades regionais através do fomento ao desenvolvimento científico e tecnológico através da tecnologia convencional nos eixos mencionados acima, expressando assim a crença na cadeia linear de inovação. Contudo, esse modelo é fortemente questionado, uma vez que a realidade do desenvolvimento científico e tecnológico vivenciado até então no país ainda não tenha se demonstrado capaz de promover o desenvolvimento econômico e social e superar as desigualdades regionais. 
Entre os atores de C\&T em Santa Catarina podemos citar as 120 instituições de ensino superior com aproximadamente 180 mil alunos matriculados em cursos de graduação e pós-graduação. No setor público tem destaque a Fundação de Apoio à Pesquisa Científica e Tecnológica (FAPESC) que desenvolve projetos como a Rede Catarinense de Ciência e Tecnologia, e conta com a parceria de instituições como Ministério da Cultura, Financiadora de Estudos e Projetos (Finep), Conselho Nacional de Desenvolvimento Científico e Tecnológico (CNPq) e o Banco Nacional de Desenvolvimento Econômico e Social (Bndes); a Empresa de Pesquisa Agropecuária e Extensão Rural de Santa Catarina S/A (Epagri); a Empresa Brasileira de Pesquisa Agropecuária (Embrapa), o Serviço Nacional de Aprendizagem Industrial (Senai); o Instituto Euvaldo Lodi de Santa Catarina (IEL/SC); e o Centro de Referência em Tecnologias Inovadoras (Certi). Nas parcerias públicas e privadas a Rede Catarinense de Entidades Promotoras de Empreendimentos Tecnológicos (ReCepet) e também, na área de parques tecnológicos o Parktec Alfa e a implantação do projeto Sapiens Park.

No setor privado entre as 5.915 empresas (indústrias extrativa e de transformação), 480 realizaram dispêndios em pesquisa e desenvolvimento (P\&D), correspondendo $8,1 \%$ do total. Esse percentual é maior que a média nacional de 5,9\% em 2003. Dentre essas empresas que implementaram inovações $92 \%$ utilizaram fontes próprias para financiar suas atividades em P\&D; os 8\% restantes estão divididos igualmente entre os financiamentos públicos e privados. Apenas 5\% das empresas inovaram no período e seus principais parceiros foram a universidade ou algum instituto de pesquisa (PCD/2015, 2006).

O Estado se configura como elemento central na articulação dos atores da C\&T, assim como no investimento e fomento do desenvolvimento científico e tecnológico. Comparando os dispêndios realizados pelos governos estaduais em P\&D entre 2003 e 2009, verifica-se, por um lado, a evidente disparidade regional do desenvolvimento científico nacional: enquanto os estados da região Norte apresentaram 345,1 milhões em dispêndios no ano de 2009, os estados da região Sudeste apresentaram 5.871,1 milhões em dispêndios no mesmo ano. As disparidades podem ser percebidas também no interior das regiões, como no caso da região Sul. Por outro lado, verifica-se um aumento significativo dos dispêndios em $\mathrm{P} \& \mathrm{D}$ realizados pelo Estado de 
Desenvolvimento geográfico desigual e planejamento em Santa Catarina: a Política Catarinense de Ciência, Tecnologia e Inovação

Santa Catarina com destaque para os anos de 2008 e 2009, correspondentes a construção e aprovação da PCCTI.

Tabela 1 - Dispêndios dos governos estaduais em Pesquisa e Desenvolvimento (P\&D), segundo regiões e unidades da federação, 2003-2009, em milhões de R\$

\begin{tabular}{|c|c|c|c|c|c|c|c|}
\hline Grandes Regiões / UF & 2003 & 2004 & 2005 & 2006 & 2007 & 2008 & 2009 \\
\hline Total & $3.705,7$ & $3.900,5$ & $4.027,3$ & $4.282,1$ & $5.687,4$ & $7.138,0$ & $8.424,8$ \\
\hline Centro-Oeste & 21,8 & 56,7 & 66,5 & 71,7 & 143,7 & 153,8 & 269,3 \\
\hline Norte & 36,3 & 41,3 & 68,5 & 125,0 & 152,2 & 245,8 & 345,1 \\
\hline Nordeste & 281,3 & 311,3 & 393,9 & 441,7 & 515,2 & 732,5 & 938,8 \\
\hline Sudeste & $3.014,9$ & $3.066,1$ & $3.006,8$ & $3.141,8$ & $4.289,8$ & $5.225,4$ & $5.871,1$ \\
\hline Sul & 351,3 & 425,1 & 491,7 & 501,9 & 586,6 & 780,6 & $1.000,5$ \\
\hline Paraná & 238,2 & 314,0 & 323,5 & 365,1 & 427,9 & 425,3 & 572,2 \\
\hline Rio Grande do Sul & 61,0 & 70,6 & 85,2 & 68,1 & 75,3 & 77,3 & 125,9 \\
\hline Santa Catarina & 52,1 & 40,5 & 82,9 & 68,7 & 83,3 & 278,0 & 302,4 \\
\hline
\end{tabular}

Fonte: Ministério da Ciência, Tecnologia e Inovação.

Em síntese: quanto ao planejamento em Santa Catarina, sobretudo, o governamental, um paralelo interessante é referente às suas inclinações autoritárias: na maior parte do período analisado, praticou-se um planejamento top-down tradicional. E isso parece não ter mudado com a Reforma Administrativa da última década e a criação das SDR, embora o PCD/2015 tenha recebido contribuições de instituições externas ao Governo.

No que diz respeito a $C \& T$ percebe-se que o termo foi utilizado no planejamento como base para a promoção do desenvolvimento econômico, e consequentemente social, através do desenvolvimento industrial. O tema passa a ganhar caráter estratégico apenas nos anos 2000 com o $\mathrm{PCD} / 2015$, e a ter um planejamento diferenciado com a criação da Lei de Inovação em 2008 e da PCCTI em 2009. Contudo, na realidade, esses esforços ainda não representaram uma modificação na dinâmica desigual do desenvolvimento catarinense. 


\section{CONSIDERAÇÕES FINAIS}

Percebe-se na PCT que o desenvolvimento científico e tecnológico tem sido considerado na medida em que promova mais desenvolvimento tecnológico, que, por sua vez deve promover mais desenvolvimento econômico e social. Porém, a realidade brasileira vem demostrando como essa experiência é problemática. Mesmo com as diretrizes que apontam para a promoção do desenvolvimento regional sustentável, do desenvolvimento econômico e da inclusão social, o desenvolvimento científico e tecnológico permanece concentrado.

No contexto do planejamento em Santa Catarina percebe-se, ao longo do tempo, forte ênfase no incentivo ao desenvolvimento econômico com vistas à superação da condição de Estado periférico quando ao restante do país. A base do desenvolvimento econômico encontra-se na acumulação de capital privado. A área social ganha espaço no planejamento a partir da década de 1980, contudo desvinculada tanto das outras áreas que compõem os planos quanto da realidade social.

A ideia de desenvolvimento regional sustentável e equilibrado compõe o planejamento após os anos 2000 e, nesse contexto, o papel da C\&T foi de suporte ao desenvolvimento econômico, através do desenvolvimento industrial. A tecnologia passa a ser um eixo estratégico do planejamento no PCD/2015 em 2006, mas um plano específico para C,T\&I só é elaborado em 2009, com a criação da Política Catarinense de Ciência, Tecnologia e Inovação. Desse modo, verifica-se uma visão conservadora de C\&T no planejamento do Estado de Santa Catarina, onde os investimentos são voltados para a tecnologia convencional com o objetivo de promover desenvolvimento econômico, sustentável, e equilíbrio regional. No entanto, o desenvolvimento da tecnologia convencional favorece a dinâmica desigual do desenvolvimento.

Dessa forma, foi possível verificar que o planejamento do desenvolvimento científico e tecnológico em Santa Catarina contribui para o desenvolvimento geográfico desigual, pois não modificou a dinâmica da C\&T existente até então. E, consequentemente, não contribuiu, como esperado, para a promoção do desenvolvimento econômico e social sustentável e ao equilíbrio regional. Isso demonstra que a evolução nos números relacionados ao desenvolvimento de C\&T não corresponde, na prática, à evolução do desenvolvimento social. 
Desenvolvimento geográfico desigual e planejamento em Santa Catarina: a Política Catarinense de Ciência, Tecnologia e Inovação

Pode-se afirmar que as características do planejamento científico e tecnológico são consequências do capitalismo periférico brasileiro, pois a contribuição da C\&T é pouco relevante tanto no processo de acumulação do capital, como no desenvolvimento econômico e social. Isso se deve, em certa medida, a configuração espacial do país, com espaços mais desenvolvidos, de um lado, e regiões pobres, de outro, a qual produz a paisagem do capitalismo; expressão do desenvolvimento geográfico desigual. O processo de acumulação que vivenciamos no período recente torna visível a dissociação entre desenvolvimento tecnológico, desenvolvimento econômico e desenvolvimento social (THEIS, 2009).

\title{
UNEVEN GEOGRAPHICAL DEVELOPMENT AND PLANNING IN SANTA CATARINA: THE "POLÍTICA CATARINENSE DE CIÊNCIA, TECNOLOGIA E INOVAÇÃO"
}

\begin{abstract}
Abtract
The relationship between the uneven geographical development and the planning process in the Brazilian Southern State of Santa Catarina can be analysed from the perspective of the Politics of Science, Technology and Innovation of Santa Catarina [PCCTI]. In this work we assume the hypothesis that the very conventional view of S\&T influences the most recent state planning initiative, and so favours the dynamics of uneven geographical development in Santa Catarina. Our analysis focuses the Santa Catarina Law of Innovation and the mentioned PCCTI. We try to criticise the argument of the linear chain of innovation on which the PCCTI and the Law of Innovation rest by mobilising the concept of uneven geographical development. Our findings show that there is a dominance of S\&T in its very conventional form in the recent decades, functional to the capitalist development in Santa Catarina. So the planning of S\&T in the referred period seems to contribute to the uneven geographical development in the State of Santa Catarina.
\end{abstract}

Keywords: Santa Catarina. Regional Planning. Science \& Technology. JEL Classification: O38, R58. 


\section{REFERÊNCIAS}

BIRKNER, Walter Marcos Knaesel. Capital social e reformas políticas em Santa Catarina: o caso dos Fóruns de Desenvolvimento Regional Integrado. 2004. 313p. Tese (Doutorado) - Departamento de Filosofia e Ciências Humanas, Universidade Estadual de Campinas, Campinas.

BUTZKE, Luciana. O papel das associações de municípios na dinâmica de planejamento regional e urbano em Santa Catarina. Estudo de caso sobre a trajetória da Associação dos Municípios do Alto Vale do Itajaí. 142p. Dissertação (Mestrado) - Programa de Pós-graduação em Sociologia Política, Centro de Filosofia e Ciências Humanas, UFSC, Florianópolis, 2007.

DAGNINO, Renato (org.). Tecnologia Social: ferramenta para construir outra sociedade. Campinas, SP: Komedi, 2010.

DAGNINO, Renato; DIAS, Rafael. A Política de C\&T Brasileira: três alternativas de explicação e orientação. Revista Brasileira de Inovação, Rio de Janeiro (RJ), 6 (2), p. 373-403, julho/dezembro 2007.

ESCOBAR, Arturo. Planejamento. In: SACHS, Wolfgang. Dicionário do desenvolvimento: guia para o conhecimento como poder. Petrópolis: Vozes, 2000. 399p. Tradução de: The development dictionary.

FERREIRA FILHO, Roberto. Planejamento governamental em Santa Catarina. [s. 1.]: Independente, 1990. 1 vídeo-cassete (120min), Color, SP.

FRIEDMANN, John R. P. Introdução ao planejamento democrático. Rio de Janeiro: Fundação Getúlio Vargas, 1959. xxiv, 196p.

GOULARTI FILHO, A. O planejamento estadual em Santa Catarina 19552002. Ensaios FEE, Porto Alegre, v. 26, n. 1, p. 627-660, 2005.

GUILLEZEAU, Patrícia. La planificación latinoamericana de la década de los 90. Revista de Ciencias Sociales, vol. VIII, n. 1, p. 95-110, Enero-abril 2002. 
Desenvolvimento geográfico desigual e planejamento em Santa Catarina: a Política Catarinense de Ciência,

Tecnologia e Inovação

HARVEY, David. Espaços de Esperança. São Paulo: Edições Loyola, 2004.

LAFER, Betty Mindlin. O conceito de planejamento. In: LAFER, Betty Mindlin (org.). Planejamento no Brasil. $3^{\text {a }}$ ed. São Paulo: Perspectiva, 1975. 187p. (Coleção debates, 21) p. 9-28.

LAFER, Celso. O Planejamento no Brasil: observações sobre o Plano de Metas (1956-1961). In: LAFER, Betty Mindlin (org.). Planejamento no Brasil. $3^{\mathrm{a}}$ ed. São Paulo: Perspectiva, 1975. 187p. (Coleção debates, 21) p. 29-50.

LOPES, Carlos Thomaz Guimarães. Planejamento, Estado e crescimento. São Paulo: Pioneira, 1990. xii, 205p.

LÖWY, Michael. A teoria do desenvolvimento desigual e combinado. Outubro, p. 73-80, 1995.

MARCON, Maria T. de Resenes; MARQUES, Valesca Menezes. As Associações de Municípios e o planejamento regional em Santa Catarina. In: SIEBERT, Claúdia Freitas (org.). Desenvolvimento regional em Santa Catarina. Blumenau: Edifurb, 2001. 244p, il p. 189-211.

MATUS, Carlos. O Plano como Aposta. São Paulo em Perspectiva. 5 (4): 28-42 out/dez. 1991.

MICHELS, Ido Luiz. Crítica ao modelo catarinense de desenvolvimento: do planejamento econômico, 1956 aos precatórios, 1997. Campo Grande: Ed. da UFMS, 1998. 242p.

PCCTI. Política Catarinense de Ciência, Tecnologia e Inovação. 2010. Disponível em: http://www.fapesc.sc.gov.br/index.php?option=com_docman\&task=doc_download\&gid=3\&Itemid $=42$.

PCD/2015. Plano Catarinense de Desenvolvimento SC 2015. Descentralização e o Desenvolvimento Regional Sustentável, 2006. Disponível em: 
http://www.spg.sc.gov.br/Planejamento/Plano\%20sc\%20de\%20Desenvolvimento/Plano_Catarinense_de_Desenvolvimento-SC2015.pdf.

PNUD. Programa das Nações Unidas para o Desenvolvimento. Regionalização administrativa e descentralização do processo de desenvolvimento catarinense (Projeto Meu Lugar - BRA/03/008). Florianópolis: Dezembro, 2004. Disponível em: http://www.pnud.org.br/arquivos/ arqui1151002066.zip.

SANTA CATARINA. (Estado). Lei Complementar $\mathbf{N}^{\mathbf{0}} \mathbf{2 4 3}$, de 30 de janeiro de 2003.

. (Estado). Lei Complementar $\mathbf{N}^{\circ} 284$, de 28 de fevereiro de 2005.

. (Estado). Lei Complementar $\mathbf{N}^{0}$ 381, de 7 de maio de 2007. . (Estado). Lei $\mathbf{N}^{0} \mathbf{1 4 . 3 2 8}$, de 15 de janeiro de 2008. (Lei da Inovação).

SANTA CATARINA, Secretaria de Estado de Coordenação Geral e Planejamento; SANTA CATARINA, Secretaria de Estado da Indústria, do Comércio e do Turismo. Diagnóstico Municipal. Florianópolis, 1990. 35p, il. (Programa integrado de desenvolvimento socioeconômico).

SANTA CATARINA, Secretaria de Estado do Planejamento e Fazenda; FECAM, Federação Catarinense de Associações de Municípios; AMUNESC, Associação de Municípios do Nordeste de Santa Catarina. Plano básico de desenvolvimento regional. Florianópolis: Secretaria de Estado do Planejamento e Fazenda, [1993]. 527p, il.

SANTA CATARINA, Gabinete de Planejamento e Coordenação Geral; FORTES, Otávio Franco. Política de desenvolvimento regional e urbano para Santa Catarina. Florianópolis: [s.n.], 1981 (Florianópolis: IOESC). 241 , mapas, gráficos e tabelas. 
Desenvolvimento geográfico desigual e planejamento em Santa Catarina: a Política Catarinense de Ciência,

Tecnologia e Inovação

SANTA CATARINA, Governo do Estado; JOSÉ BONIFÁCIO, Fundação Universitária. Relatório Preliminar: Indicações Estratégicas. Fevereiro, 2005. Disponível em: http://www.spg.sc.gov.br/planejamento/arquivos/ SC_FUJB_Relatorio_Preliminar_fev05.pdf.

SCHMITZ, Sérgio. Planejamento estadual: a experiência catarinense como Plano de Metas do Governo - PLAMEG, 1961/1965. Florianópolis: Ed. da UFSC, 1985. 133p, $21 \mathrm{~cm}$.

SIEBERT, Cláudia Freitas. Panorama do planejamento regional em Santa Catarina: da centralização à construção da solidariedade regional. In: SIEBERT, Claúdia Freitas (org.). Desenvolvimento regional em Santa Catarina. Blumenau: Edifurb, 2001. 244p, il. p. 139-166.

SMITH, Neil. Desenvolvimento desigual: natureza, capital e a produção de espaço. Rio de Janeiro: Ed. Bertrand Brasil, 1988.

THEIS, I. M.; BUTZKE, L. O paradoxo da geografia no capitalismo mundializado: revisitando a lei do desenvolvimento desigual e combinado. In: Anais do $6^{\circ}$ Colóquio Internacional Marx e Engels. GT 4 - Economia e política no capitalismo contemporâneo. 2009.

Tecnologia e território na periferia do capitalismo mundializado: tentativa de desconstrução da visão hegemônica de C\&T no Brasil. Anais do XIII Encuentro de Geógrafos de América Latina - San José, 25 al 29 de Julio de 2011.

UFSC. Universidade Federal de Santa Catarina; PPGE. Programa de PósGraduação em Economia. Programa Estratégico de Desenvolvimento com Base em Inovação. Relatório Geral. Florianópolis: Outubro, 2005. 